\title{
La noche de Europa (2017), Dionisio Cañas. ¿Cómo escribir poesía ante la urgencia?
}

La nuit de l'Europe (2017), Dionisio Cañas. Comment écrire de la poésie face à

l'urgence?

\section{Claudie Terrasson}

\section{(2) OpenEdition}

Journals

\section{Edición electrónica}

URL: https://journals.openedition.org/agedor/5990

DOI: 10.4000/agedor.5990

ISSN: 2104-3353

\section{Editor}

Laboratoire LISAA

\section{Referencia electrónica}

Claudie Terrasson, «La noche de Europa (2017), Dionisio Cañas. ¿Cómo escribir poesía ante la urgencia?», L'Âge d'or [En línea], 13 | 2020, Publicado el 01 octubre 2021, consultado el 15 octubre 2021. URL: http://journals.openedition.org/agedor/5990 ; DOI: https://doi.org/10.4000/agedor.5990

Este documento fue generado automáticamente el 15 octubre 2021.

L'Âge d'or. Images dans le monde ibérique et ibéricoaméricain 


\title{
La noche de Europa (2017), Dionisio Cañas. ¿Cómo escribir poesía ante la urgencia?
}

\author{
La nuit de l'Europe (2017), Dionisio Cañas. Comment écrire de la poésie face à \\ l'urgence?
}

Claudie Terrasson

1 Este estudio propone una serie de reflexiones sobre el último poemario (2017) de Dionisio Cañas, La noche de Europa ${ }^{1}$, en el que se evoca la situación de los refugiados en las islas griegas, precisamente en la isla de Lesbos. Se trata de un libro escrito en parte en el mismo momento de la crisis cuyos ecos se encuentran en la prensa de ese momento. Más allá de este caso de urgencia, el libro plantea la cuestión general de las urgencias llamadas humanitarias, de su tratamiento por los medios (escenificación y espectáculo de la urgencia), de su significado humano, social, político; también cuestiona el papel del escritor o artista y su capacidad de creación ante la urgencia vivida directamente o a partir de los recuerdos de tal realidad: " Pasado el primer impacto del retorno a la ramplona realidad española, los detalles de mi viaje a Lesbos emergen como fragmentos de un naufragio emocional"2 concluye el yo poético (51).

2 A la hora de redactar, una puede dudar en definir la urgencia como humanitaria, humana, social, política, etc. La dificultad de designar e identificar la urgencia resulta candente como lo demuestra la abundancia de fórmulas diversas para hablar del caso de los refugiados: "urgencia climática, económica, militar"; tales expresiones designan las causas (clima, miseria, guerra, represión etc.) que generaron la urgencia y que la definen, causas por las que huyeron los hombres; ahora ison estos refugiados, o migrantes? Idéntico problema de designación se plantea con el término "migrante" que resulta poco adecuado, más será una forma de eufemismo que escamotea la realidad tal como lo denunciaba irónicamente Roland Barthes en Mythologies's: se habla de los migrantes callando las causas objetivas de su huida como si fueran seres que se pasaran la vida migrando tales las aves, como si su destino fuese el de eternos desplazados, con lo cual se descarta cualquier perspectiva de encontrar un lugar de acogida. Cuando se 
dice urgencia humanitaria, y parece ser el caso aquí, refiere tal expresión una situación efectiva que no es sino consecuencia de las causas anteriores. Con lo cual, una primera reflexión que conduce a postular que la voz urgencia designaría tanto los factores (clima, guerra, miseria etc.) como la situación misma en una temporalidad condensada y acelerada que funde causa y consecuencia. Por eso, los medios asimilan urgencia y crisis muy a menudo, lo que participa de una operación de captación de su historicidad, la cual viene sustituida por la dramatización y el afecto. Volvemos pues a la cuestión del papel social del artista ante tal subterfugio.

\section{Presentación}

Del poeta mencionaremos únicamente los datos biográficos que aparecen dispersos en el libro. Dionisio Cañas, poeta nacido en 1949 en La Mancha, conoció el exilio con su madre a Francia (París), luego se fue a vivir y trabajar en Estados Unidos (Nueva York) antes de volver a la Mancha ${ }^{4}$. Los estudiosos de poesía conocen su abundante obra poética, artística y crítica, aparece ésta presentada en la página del autor, https:// dionisioc.com/ lo mismo que una breve biografía.

4 Entre dichos estudiosos, Claire Laguian escribe lo siguiente: "El último poemario del artista y crítico Dionisio Cañas, La noche de Europa (2017), se compromete en denunciar la hipocresía del continente europeo en relación con su manera de tratar y (no) acoger a las personas que migran." ${ }^{5}$ Resumen estas palabras el tema que sustenta el propósito y discurso del poeta. Se sitúa pues este libro dentro de lo que se llamaría poesía comprometida, sabiendo cómo el compromiso hoy se expresa bajo formas distintas de lo que pudiera hacer en los 50. Digamos que se inserta en una corriente multiforme que abarca tanto la vuelta a un realismo cívico o ético como el activismo. Por consiguiente, el lector puede tener reparos en considerar el libro como poemario a pesar de que el propio autor lo designa así; se explica por su dimensión muy heterogénea o híbrida, la cual incide en su significado último.

\section{Aproximación al libro}

5 De ahí que resulte imprescindible hacer una presentación detallada de La noche de $E$ Europa ${ }^{6}$ por no coincidir el libro con las normas canónicas, por las rupturas formales, las singularidades discursivas, la hibridez genérica que lo caracterizan, hasta el extremo de que se plantea la pregunta legítima de su designación. ¿Poema, poemario, ensayo, panfleto, (incluso) performance?

En efecto, además de una serie de textos (poemas y prosas), incluye el libro una foto montaje del propio autor tumbado en una playa de Lesbos como si fuese él un refugiado víctima de la travesía en barco, imitando las fotos a las que nos vamos acostumbrando; participa la foto de un proyecto llamado "http://www.acciónrefugiados.es" con enlaces (fotos, documental) en Facebook. Esos elementos propios de las redes sociales más sugieren el ámbito y el discurso de una ONG o de un colectivo de ayuda a migrantes que los de un poemario. El libro incluye también un disco concebido por Dionisio Cañas Las ocho puertas de la noche (un collage de voces y sonidos): son fragmentos de canciones diversas, archivos de radio, de textos leídos por el propio autor (Recordemos que se publicó el libro en la colección "Palabreadorxs" subtitulada como "colección para leer a 
viva voz") $)^{7}$. Tampoco es de extrañar sabiendo que Dionisio Cañas como lo recuerda su antólogo "siempre ha estado buscando nuevas fórmulas de expresión poética: el performance, la acción, el arte, las presentaciones de libro, los objetos, las fotografías, el vídeo...etc."”, incorporando así la herencia de las prácticas artísticas rupturistas de vanguardias. Sólo que en este libro parece jugar de modo mucho más radical con las fronteras genéricas, discursivas, estéticas.

Conviene entonces preguntarse si la hibridez formal constituye una forma de respuesta sin duda contundente ante la urgencia; o si es también síntoma de una situación de escritura presa de la urgencia, síntoma entonces de las circunstancias empíricas que fueron las del mismo autor en el momento de la creación. O sea que el libro manifestaría por su heterogeneidad en la composición, en la discursividad, en lo estético, lo que fueron las circunstancias y condiciones de posibilidad de escritura que vivió el propio Dionisio Cañas. De hecho, nos cuenta él la urgencia de aquel momento: cómo ante la urgencia humanitaria de los refugiados en las islas griegas, ante la difusión multitudinaria de la foto de un acontecimiento (el niño ahogado encontrado en una playa de Turquía), decidió hacer algo, viajar a Lesbos para montar un taller, un proyecto de escritura colectiva:

[...] en agosto del año 2015 [...], yo empecé a pensar en " ¿Qué puedo hacer para ayudar a los refugiados?" Entonces se me ocurrió que debía ir a la isla de Lesbos para hacer allí mi taller de escritura participativa "El Gran Poema de Nadie". [...] Al volver a Atenas, [...] en el barco en el que viajaban los refugiados, hice amistad con un militar irakí cristiano que venía huyendo de las amenazas de muerte del Estado Islámico. Una fugaz aventura amorosa con este hombre se convertiría en la clave para poder terminar mi poema "La noche de Europa". (36)

8 En la cita queda claro que el propio autor designa si no su libro (a falta de cursivas), por lo menos parte de él como poema: la primera sección lleva efectivamente este mismo nombre; otras dos secciones también pueden considerarse formalmente como poesía.

Por eso importa describir la arquitectura del libro y su composición tan híbridos como ya dije e interrogar su significado en cuanto a la relación escritura y urgencia.

\section{Arquitectura, género, discursividad, temática}

Lo relevante es la dimensión contrastada y paradójica del libro. Por una parte, se observa una arquitectura externa muy marcada mientras que por otra parte presenta el conjunto una total hibridez genérica y discursiva, asociada a un constante flujo verbal, a veces mero flujo sonoro, puro grito. Por fin, señalemos que coexisten ambas dimensiones dentro de una fuerte continuidad temática: la postura de Europa ante la tragedia de los refugiados, o sea la pasividad ante la urgencia.

11 Esta arquitectura externa es la de un libro que consta de ocho partes, identificadas todas por un título: "La noche de Europa" (11-31), "Cuaderno de Lesbos" (35-51), "La noche del mundo" (55-58), "La traición de Europa" (61-62), "La noche de los tiempos" (64-69), "Maldita sea, la poesía me ha hecho un desgraciado" (71-76), "Las ocho puertas de la noche" (77-86), "Proyecto" (87-89). De estas 8 secciones, 7 son textos, siendo la octava sección la foto-collage ya mentada, en cuanto a los siete textos, seis son de Dionisio Cañas.

Si miramos el criterio del género, notamos primero variedad y discontinuidad. Se puede ver en el libro un "extenso poema" en prosa (designado así por Cañas, 35) compuesto de 
tres momentos: "La noche de Europa" (11-31), "La noche del mundo" (55-58) y "la noche de los tiempos" (64-69). La unidad temática se construye alrededor de la voz "noche" (sinónima aquí de oscuridad y muerte en relación con los epígrafes iniciales de Zambrano, Cañas, Heidegger), igualmente aparece un efecto de amplificación (de un continente, al universo, a la Historia) y un efecto de desplazamiento (del espacio al tiempo). Considerando solo estas tres secciones podríamos concluir que forman un poema por su unidad y continuidad, formal y temática, pero van separadas por otros textos, lo cual acarrea una discontinuidad genérica, discursiva y temporal.

El tríptico poético viene interrumpido dos veces seguidas: primero por un texto definido como un diario, "Cuaderno de Lesbos" (sección 2); canónicamente obedece a las pautas del género, lleva las fechas precisas de la escritura (va del 24 de enero de 2016 al 3 de febrero del mismo año, incluso se notan de modo casi maniático las horas precisas), incluye topónimos precisos de Grecia (Mitilene, Atenas, isla de Quíos, Lesbos...). Se trata de un texto narrativo escrito por un yo: cuenta las circunstancias de su viaje a Grecia, su estancia en Lesbos, sus encuentros con los refugiados, también encierra reflexiones y meditaciones. Este diario constituye la arqueología del tríptico poético, aclarando pues su escritura en situación urgente. En cuanto al segundo texto "La traición de Europa" (sección 4) insertado en el tríptico, genera una ruptura mucho más fuerte (señalada visualmente mediante las cursivas) por ser alógeno (es del artista catalán Francesc Torres) y por ser un discurso-manifiesto que denuncia "la inacción criminal de Europa" (62) en los 90 cuando la guerra de los Balcanes. Se introduce así un contexto temporal anterior y otra urgencia acarreada por otra guerra.

En la sección 6, reaparece la figura del propio poeta en un texto en el que toma la palabra "Maldita sea, la poesía me ha hecho un desgraciado"; Dionisio Cañas hace un balance de su obra poética, de la poesía ante la realidad replanteando entonces la pregunta de Hölderlin warum Dichter ... (citada en el epígrafe de Heidegger) y anunciando al final su retiro: renuncia a seguir escribiendo poesía. Este balancemanifiesto poético y vital sirve de conclusión a lo que sería propiamente dicho el libro. Luego viene el conjunto de textos de las siete grabaciones del disco y la sección titulada "Proyecto que presenta la foto montaje y el enlace de la página web de Acción refugiados con documental, más fotos, y otros elementos propios de las redes sociales".

Es posible interpretar en un primer momento estas rupturas y la hibridez extrema como traducción de una situación de urgencia, siendo el libro puro testimonio de momentos acuciantes y trágicos por falta de respuesta institucional ante la urgencia.

\section{Europa o una nueva Babel}

Para cualquier lector es relevante otra hibridez que es la de la discursividad (con rasgos marcados, sean formales, temáticos, estéticos). Igualmente participa de un propósito crítico, siendo la misma escritura una herramienta de denuncia.

De entrada, se nota la práctica del collage de idiomas varios, con traducciones o no: el idioma español viene entrelazado con otras lenguas: el francés " $C e$ toit tranquille où marchent des colombes [...] La mer, la mer toujours recommencée"(11), o el inglés, "Is this the Europe what we want?"(12); "This is not the Europe what we want. Esta no es la Europa que queremos." (18), declinado también bajo formas de citas (identificadas mayoritariamentes) como " I put my arms around him yes and drew him down to me so he could feel my breast all perfume yes I said 
yes I will Yes Al parecer no vivía ni estaba muerta, querido James (13). O como "Y tú, Dylan Thomas [...] me decías: Do not go gentle into that good night. _-___Rage, rage against the dying of the light"(29). Más fugazmente aparece el alemán a través de la letra de Lili Marleen, Ich bin von Kopf bis $\mathrm{Fu} \beta$ auf Liebe eingestellt, estoy a punto de amarte de los pies a la cabeza (21). La presencia del griego y del árabe se manifiesta en los nombres de lugares o personas, recreando al final una situación babélica en que coexisten culturas e idiomas que intentan comunicar. Este collage lingüístico no es decorativo sino político; su finalidad es recordar y recrear lo que fue/es/sigue siendo históricamente el Mediterráneo, un mar situado entre tierras y que las une, un mare nostrum, o sea un espacio propicio a cruces, encuentros, contactos entre culturas diversas. El collage deshace las fronteras levantadas por los países europeos. Dionisio Cañas nos propone leer un libro sin fronteras de lenguas para denunciar a una Europa que levanta cada vez más muros. Cuando cita a Valery, opta por versos sacados de "Le cimetière marin", lo hace evidentemente (y lo dice además) por haberse convertido hoy el Mediterráneo en auténtico cementerio, transformado en territorio delimitado por fronteras y prohibiciones. Subvierte el significado inicial del poema de Valery (serenidad, belleza, tono elegíaco, meditación sobre lo efímero de la vida...). De modo que los conocidos versos "Ce toit tranquille où marchent des colombes" [...] (11) suenan dolorosamente y adquieren aquí matices de humor negro. Igualmente, convocar la figura de Ulises (el de Homero y el de Joyce) participa de la misma intención crítica: equiparando a los refugiados con este personaje mítico de la gran tradición épica europea, reivindica Cañas el estatuto de héroe para los refugiados. Afirma en efecto su heroicidad porque se enfrentan con la muerte navegando por el Mediterráneo y con una urgencia tan vital y trágica como fue la de Ulises volviendo a Ítaca. El collage lingüístico e intertextual desempeña una función esencial de denuncia.

18 Terminaré este punto subrayando que, si Cañas practica un collage de voces diversas, las de la actualidad, voces de la tradición cultural (literaria, filosófica) de Europa (o de fuera) nunca lo hace de forma mecánica, evitando la facilidad del procedimiento sistemático.

Es imprescindible señalar otra marca visual notable, el uso de una puntuación propia, con guiones extensos, horizontales (y no barras oblicuas a la manera por ejemplo de Juan Gelman). Esas interrupciones quiebran el desarrollo y el ritmo de la palabra, imponen silencios haciendo más sensible e impactante la violencia de la situación de urgencia, materializan y visibilizan el silencio y la ausencia de reacción de los países europeos ante la urgencia humanitaria de los refugiados. No se puede sino concluir provisionalmente sobre la dimensión obviamente transgresora del libro, es la más llamativa. Se intenta romper el molde de los discursos dominantes, culturales y políticos, imperantes en el momento de la escritura, retomando las rupturas de las vanguardias como ya lo anticipé, (aun cuando hoy se considera que muchos de esos recursos rupturistas pasaron a ser tradición). Escribió Dionisio Cañas un libro en que derrumbó las normas académicas, genéricas, quiso crear un libro sin fronteras para protestar contra las de Europa, contra los muros levantados ante los refugiados. Más allá de la protesta contra la urgencia, la dimensión inmediatamente más llamativa, importa considerar la cuestión de la escritura ante la urgencia: esta fragmentación e hibridez extremada del poema quizás sea la única forma de expresión después del acontecimiento traumático de Lesbos. Aquí la urgencia 
informa pues la escritura del creador y deja sus huellas en ella imposibilitando cualquier otro modo expresivo.

21 Interesa volver a la cuestión de la intertextualidad, no es mero juego narcisista ni collage estético sino procedimiento textual con clara finalidad subversiva como se acaba de ver con la cuestión de los idiomas. La intertextualidad principal se establece con el libro de María Zambrano, y lo comenta así Dionisio Cañas:

Cuando hace unos años empecé a escribir "La noche de Europa" yo no podía sospechar que iba a terminar este extenso poema en Grecia, en la isla de Lesbos; siempre acompañado por el libro de María Zambrano La agonía de Europa. (35)

\section{De La agonía de Europa a La noche de Europa.}

El poeta se fue a Lesbos "acompañado por el libro de María Zambrano La agonía de Europa" (35). Recordemos que la filósofa publicó La agonía de Europa en 1945 en Buenos Aires donde vivió exiliada cierta temporada. Se conecta pues con el momento histórico de la segunda guerra mundial, y para una española republicana exiliada con la derrota de la 2da república; constituye así el libro una reflexión crítica sobra la cultura europea en que María Zambrano expone sus interrogaciones y preocupaciones nacidas de las crisis sucesivas que vivió la Europa de aquellos años. Pese a un contexto que fue el de una serie de desastres, la filósofa siguió conservando una forma de esperanza y de fe en Europa y su cultura (la de la Mitteleuropa) como si no se resignara a aceptar su desaparición. En el libro de Cañas, La agonía de Europa aparece constantemente como hipotexto explícito; es referencia obvia y reivindicada mediante un diálogo con la filósofa a la que interpela el yo poético, mediante títulos y citas constantes, mediante un trenzar-collage de dos discursos: por una parte, el discurso del yo que denuncia la inacción de Europa frente a la urgencia y por otra parte, en cursivas, leemos el discurso de María Zambrano. En la primera sección poética, "La noche de Europa", la voz de un hablante autodesignado como "Dionisio" va comentando y criticando, con auténtica saña, extractos de La agonía de Europa. Alternan sus comentarios y los fragmentos de Zambrano, él los cuestiona sin cejar, levantando contradicciones unas tras otras. Así pasa cuando María Zambrano afirma la existencia irreductible de Europa:

Pero aun en medio del terror, el amor no se resigna y sigue preguntando si en verdad ha muerto esa realidad histórica de vida y de cultura, esa tradición que llamamos Europa, Europa no puede reducirse a un fantasma dócil al conjuro de la imaginación. Y es que el amor no se calma con fantasmas. Tiene hambre de realidad. (29)

Le contesta el yo poético, no sin ironía, retomando algunas de las palabras de la filósofa, recusando el discurso metafórico y teórico de Zambrano y optando por un discurso denotativo, concreto, situado en un espacio y un tiempo determinados:

"Yo me fui a la realidad querida María Zambrano, porque lo real era miles de ahogados_-_-_-_en las costas de Lesbos, y lo real respondió con miles de abrazos calurosos_______de millones de refugiados que huían de la Muerte._________-_El beso de un árabe me devolvió la vida (29)

Dialoga así con María Zambrano, en ese diálogo fantasmal que ocupa toda la primera sección, como si quisiera convencerla de su error en seguir esperando algo de Europa, en invocar el amor. Otra intertextualidad que suena totalmente inapropiada en este contexto de urgencia y otro hipo texto subvertido que habla de amor es el de Juan de la Cruz: "la noche oscura de lo humano" 24, 28). Juan de la Cruz cuenta y canta el amor 
místico a Dios mediante el de la esposa al esposo, la fábula da a sentir y entender la fuerza del amor que lo ilumina todo y permite orientarse dentro de la oscuridad, por eso la noche oscura es paradójicamente una noche "dichosa". Es una noche de goceabandono paroxístico como lo manifiestan las palabras de la esposa: "cesó todo y dejéme,/dejando mi cuidado/entre las azucenas olvidado." Las nociones de abandono y olvido adquieren matices contrarios al insertarse en la evocación de la urgencia de los migrantes, resultan totalmente trágicos al significar la muerte. Dionisio Cañas desvía la referencia para denunciar la tragedia humana, critica el olvido de Europa con las repeticiones litánicas y violentas que descartan cualquier dimensión religiosa. Lo mismo hace con un poema canónico de la historiografía literaria española, él de Dámaso Alonso, poeta católico, integrado a la sociedad nacional católica. Cita Cañas el principio tan conocido de "Hijos de la ira" y en seguida lo desvía:

Madrid es una ciudad de más de un millón de cadáveres (según las últimas estadísticas). A veces en la noche yo me revuelvo y me incorporo en este nicho en el que hace 45 años que me pudro, y paso largas horas oyendo gemir al huracán, o ladrar los perros, o fluir blandamente la luz de la luna sobre las pateras sin nombre donde llegan hermosas mujeres embarazadas y Europa es el postre que nos toca esta noche [...] (15)

De este poema emblemático de la posguerra española que cobra la forma de la confesión poética de un ser desarraigado y melancólico, Cañas hace un texto devastador por revelar el envés de Europa. Los diálogos con otros muchos poetas, escritores o artistas (Dylan Thomas, Valery, Joyce, Marinetti, TS Eliot, Ezra Pound, Jorge Guillén, Dámaso Alonso, Pepe Hierro, Lorca, Heidegger, Marcel Duchamp, Edward Munch, Ay Weiwei ...) se suceden con ritmo rápido, casi brutal y le sirven para llevar a cabo una empresa de desmistificación: mostrarle al lector la verdad de Europa. Incluso dialoga Cañas consigo mismo citando sus propios versos (27-29); desarrolla una forma casi de delirio verbal en que van sucediéndose citas identificadas o no, lemas, "Is this the Europe what we want?" (12), "Yankee, go home" (23), referencias, "Edith Piaf, Marleen Dietrich, Lili Marleen , Eduard Munch" (23”), series de monosílabas, "Sí, no, sí, no, sí, no, sí, no, sí, NO” (25), onomatopeyas, "Hip hop, hip hop, hip hop, hip hop, hip hop...RAP" (21-22), onomatopeyas imitativas, "Eres la risa de las ametralladoras __-_-_-_Tra, tra, tra, tra, tra, tra, tra, tra...._-_-_-_ ¿Escuchas cómo entran las balas en la carne del recién nacido?" (55).

26 La dimensión que califico de logorrea o delirio verbal, este flujo verbal, más bien sonoro, nutrido de contantes reiteraciones, repeticiones (plétora de anáforas en particular) son claramente miméticos del flujo del mar, del flujo de los refugiados, del flujo de los muertos:

[...] están todos muertos. No lo he dicho con claridad: M U E R T O S. Todos muertos, muertos de la muerte más atroz: el invierno del corazón. ___ Están todos muertos, con los ojos congelados. _--_Quizás alguien no me ha entendido: _-_-_muertos, muy muertos, absolutamente muertos, demasiado muertos, muertos, muertos, muertos... Están muertos los corazones europeos, que miran para otro lado _____cuando le hablan de refugiados. Están todos muertos, _-_____os políticos cuando rescatan bancos en lugar de rescatar a ciudadanos. (28)

Huelga decir que la oralidad, el ritmo y los efectos sonoros contribuyen también a crear la sensación de un delirio verbal sin fin, de un caos discursivo que quiere traducir la tragedia y la urgencia de una situación que se ha banalizado. De ahí que el yo interpele a la filósofa: “ Quizás no te lo he dicho, bastante claro María Zambrano 
es ahora cuando estamos de nuevo viviendo la noche oscura

de lo humano, es ahora cuando te busco y te llamo que estamos todos muertos". (28).

\section{De la intertextualidad a la metatexualidad.}

La metatextualidad marca el paso de la transgresión a la reflexión acerca de la creación en situación de urgencia. Esta acaba por convocar la cita hölderliniana, warum Dichter, provocando así una reflexividad de la palabra poética interrogándose sobre su papel. Se desarrolla en particular al final de las secciones 2 y 3. "La noche del mundo" es una sección muy escueta en que Cañas vuelve a plantearse la cuestión eterna de la escritura poética y la utilidad social del poeta. La discursividad sigue tan incontrolada, aparentemente, el hablante va enumerando caóticamente casos de urgencia, desastres y elementos biográficos: "una manera de amor prohibido por los hombres del libro Amor anal, boca a boca, [...]" (56), "Metralla, sangre y metralla" (57). Se desprende la impresión de presenciar el apocalipsis, mientras la incoherencia de los tiempos verbales sin continuidad alguna, acentúa la sensación de caos. Conlleva aquello un cuestionamiento claro de la poesía y de su performatividad ante lo real mediante la metaforización del poema-cuerpo y del poeta-cirujano:

“[...] abierta de nuevo la herida de la página en blanco, ahora te toca a ti coser las palabras una a una tinta-sangre-semen, poema en un manto de oscura melancolía. nada, sino un poquito de amor". dejar que cicatrice el Tú que a nadie le pediste

qué poetas en tiempos de miseria? (58). Marca distancia ante los poetas del compromiso de los 50, incluso ante José Ángel Valente aunque afirmó él su fe en el poder de las palabras con suma humildad ("No inútilmente“) a pesar de no saber cómo, cuándo y dónde; Philippe Jaccottet se interroga de modo semejante:

On a bien le droit de se demander pour finir quelle sera la place [du] poète dans ce temps où le réel est chaque jour mieux dissimulé par un vacarme dépourvu de sens, sinon d'efficacité. Quelques-uns pensent qu'aux moments de crise extrême seule l'action pure se justifie. [...] J'envie ceux qui peuvent répondre à de telles questions $[\ldots]^{9}$

Aún así concluye Philippe Jaccottet, la misma inutilidad de la poesía hace que ella no sea totalmente inútil. Cañas rehuye de tal planteamiento filosófico, oponiéndole en esta sección una acumulación de sintagmas que refieren todos casos concretos, documentados o elementos de vida privada e íntima que surgen a lo largo del discurso sin aparente lógica.

Relativamente a tal cuestión, o sea el papel del poeta ante la sociedad, interesa abordar la manera con qué Dionisio Cañas trata la urgencia: habla de ella como acontecimiento mediático y como crisis, como hecho histórico adoptando un enfoque crítico e interpretativo.

\section{Urgencia: acontecimiento mediático}

Es obvio que Cañas invita al lector a reflexionar sobre la falta de actuación de Europa y la carencia de acción ante el desastre del Mediterráneo. 
considerarse el éxodo repetitivo, banalizado, acallado, silenciado como acontecimiento? A todas luces, no, ya que los medios lo ignoran a no ser que algún hecho despierte de nuevo curiosidad o empatía, suscitando un impacto fuerte en el "público". Fue el caso con la foto del niño ahogado en la playa que el autor refiere en su diario citando in extenso el comentario que se hizo del caso en Telesur, el 6 de septiembre de 2015 (45-46): evoca la dimensión espectacular del tratamiento de la urgencia mediante la recurrencia de la voz "pantalla": "En la pantalla del televisor" (57), "Las pantallas te azotan con las noticias de otros muertos más" (55). muertos en el Mediterráneo por la misma acumulación de fotos; la competencia audiovisual (casi guerra) de las imágenes manifiesta que estamos dentro de una sociedad del espectáculo y de la comunicación tal como lo teorizaron Mac Luhan o Guy Debord. Pierre Nora en un artículo canónico de 1974, "Le retour de l'évènement"10, propone definir el acontecimiento a través de su relación con los medios: para Nora, no existe el acontecimiento fuera de ellos y fuera de la publicidad que le dan los "mass media". Comentando este artículo, Alban Bensa obyecta que tal postulado acarrea el riesgo de confundir el acontecimiento mismo con su manifestación espectacular ${ }^{11}$. Precisamente observamos cómo Cañas tiene consciencia de esta dificultad, protesta con un libro que quiere romper la fascinación del instante creada por los medios, denuncia la esclavitud que supone la pantalla y la forma de drogadicción nueva que genera. Personifica las pantallas, "una pantalla envenenada que vomita noticias, de políticos corruptos, imágenes de muertos en las playas" (Cañas, 2018: 15); es manera de sugerir el control que ejercen las pantallas sobre las mentes (lo que ya denunciaron Orwell, Foucault...):

Las pantallas apagadas

las pantallas apagadas de todos los ordenadores del mundo

abrirán los ojos para ver de todos los móviles del mundo cómo caen hechos pedazos los satélites [...]

(56)

Hablar de control es apuntar la construcción del acontecimiento en tanto que espectáculo. Sin embargo, el acontecimiento es un hecho, una realidad plena y entera. Para poder superar el riesgo de negarla, es necesario volver a su historicidad y desvelarla.

\section{La urgencia como hecho histórico. De 1945 a 2017}

Lo que define el acontecimiento es la creación en el tiempo de un antes y un después. Así es cómo analizan Eric Fassin y Alban Bensa el hiato que supone la irrupción del acontecimiento. Postulan que marca una ruptura en la continuidad temporal y por consiguiente cuesta entenderlo.

Habiendo vuelto a España, Dionisio Cañas se interrogó acerca del impacto de la realidad de Lesbos, constató que la realidad que él descubría le resultaba 'un tanto irreal' (50). Tomó consciencia de un cambio de percepción: [...] después de haber vivido una realidad tan poderosa como la de Lesbos todo me parece eso, anodino e irreal." En un segundo tiempo recordó su experiencia del 11-09-2011: "Algo semejante me pasó después del 11-09-2011 en Nueva York. Desde entonces no había tenido esa sensación de que la nueva realidad ('the new real') es muy irreal". (50) 

acontecimientos similares? Lo que sí es patente es que él establece lazos entre momentos históricos desconectados, creando una serie. El interés de la categoría de serie y el interés de insertar un hecho dentro un conjunto es que descarta el concepto de crisis: hablar de crisis es negar la posibilidad de comprensión, privilegiando un pensamiento más mágico que racional. Por otra parte, incluir la urgencia humanitaria de los refugiados en un tiempo más largo permite salir de la tiranía de la urgencia que imponen los medios de comunicación, escapar de la ideología de la inmediatez y de lo instantáneo, también de la del presentismo. La serie permite pues evacuar las reacciones puramente sentimentales y privilegiar la reflexión con el tiempo necesario que esa requiere. varios momentos históricos, momentos de urgencia y solidaridad. Estando en Lesbos y viendo la miseria de los refugiados, el poeta recuerda la emigración de su propia familia, emblemática del éxodo económico de los españoles: "Recuerdo que en efecto, cuando en los años sesenta emigramos a Francia, nos llevamos lo mínimo que podíamos llevar, como esta familia de refugiados." (43). Da así una clave de comprensión del acontecimiento, estableciendo un nexo entre las dos huidas a pesar de ser económica la una (la de los 60), vital la otra (la del 2016) como lo cuenta el refugiado sirio; “Todo lo que tenía quedó sepultado cuando bombardearon su casa en Alepo, Siria" (42). Establece igualmente una conexión patente cuando desarrolla la evocación de la figura materna en la frontera hispano-francesa: "[...] llorando y pidiendo dinero para seguir el viaje" (43). Es una figura entre desoladora y enérgica por ser una mujer que dentro del caos sigue de pie, luchando a pesar de las lágrimas. Al contar la reacción de solidaridad que les permitió a la madre y al hijo seguir el viaje a París en aquellos 60 (conocidos como "los años del frío y del hambre") sugiere entonces la necesaria continuidad de tal solidaridad con los refugiados de hoy. La misma madre lo afirma al mirar la foto de la 
familia siria refugiada: "Si son como nosotros" (43) dando ella también un elemento de comprensión de la situación en tanto que idéntica urgencia.

Haber insertado el texto de Francesc Torres en el que se denuncia la pasividad de la comunidad europea ante las guerras de los Balcanes (años 90) obedece a semejante propósito de vincular acontecimientos de diversas épocas: “[...] Europa no intervino porque, claro, nosotros somos gente civilizada" (62), estigmatiza "la inacción criminal de Europa" (62). Este texto alógeno hace eco a los textos de Cañas a la par que manifiesta una continuidad histórica. En realidad, la muy aparente ruptura formal manifiesta con fuerza la continuidad de la política europea, y mundial designada como “[...] pura y simple negligencia criminal” (Ibid.). Establece Francesc Torres una analogía entre la segunda guerra mundial y la de los Balcanes al evocar "[...]campos de exterminio, limpiezas étnicas y migraciones masivas [...]" (61). Al usar un léxico identificado con el periodo nazi para hablar de los Balcanes, muestra lo urgente de la necesidad de intervenir en el conflicto.

De la sección 1 a 5, la discontinuidad temporal permite poner de relieve la continuidad de una política hecha de inacción y cinismo.

Si el efecto primero de tales episodios en un libro caótico, sin cronología y sin jerarquía entre los hechos es emotivo, su finalidad es ante todo crítica. Al situar el episodio de los refugiados dentro de una serie, crea una lógica para que emerja una posibilidad de comprensión, así es como convoca otros muchos acontecimientos como son los de la primavera de Praga, del mayo francés, de la guerra del Vietnam, de los atentados de Londres, Niza, París, Siria, las Twin Towers de NYC, etc. Interesa observar cómo Dionisio Cañas establece analogías, da saltos temporales volviendo a épocas lejanas, otras veces a tiempos más próximos. En su logorrea interminable y compuesta de series de fragmentos, Cañas recupera los recuerdos de las otras matanzas como fueron los atentados en Londres y Francia y en una misma enumeración los reúne con lo que está pasando con los refugiados: "Es el recuerdo de tantos muertos en París en Londres, en Niza, en Lesbos..." (24) No aísla la situación urgente de los refugiados como si fuera una crisis, es decir un acontecer inesperado e incomprensible, sino que opera todo lo contrario para hacer que aparezca la dimensión inteligible de la urgencia mediante su historicidad.

Volviendo a un elemento comentado en la introducción, a saber, la construcción del libro, aparece ahora que tal arquitectura híbrida de discontinuidad discursiva y temporal responde a la voluntad de operar este cruce de épocas y acontecimientos que los aclare y permita su comprensión. La arquitectura del libro va construyendo una serie de urgencias sin seguir la cronología del XX-XXI: esa construcción, habiendo superado el lector una primera impresión de caos, da acceso al significado de la urgencia.

\section{Urgencia y abandono de la escritura.}

Así lo interpretaron los medios y los comentaristas en sus reseñas de la lecturaperformance que dio Cañas. Eso parece significar el propio Cañas ante la urgencia de Lesbos y dentro de una reflexión sobre la relación poesía e historia: “¿Puede la poesía cambiar el mundo? La respuesta es NO. Pero ¿puede el mundo cambiar la poesía? La respuesta es, definitivamente, SÍ. (44)" Luis Antonio de Villena matiza la intención de dejar la poesía al escribir "el poeta que dice dejar de serlo [...]" ${ }^{14}$, sugiriendo así la 
diferencia entre dejar de ser poeta (estatuto social, función de autor...), y dejar la poesía. La experiencia de Lesbos fue un momento clave en la vida del creador como del hombre como se nos sugiere al final de la primera parte: "[...] hay un nombre, un hombre que se busca a sí mismo. Ahora sabe que todo ha sido una cruel mentira, un juego del cadáver invisible de la vida. [...] Escribiendo quema toda posibilidad de ser feliz" (31). Sin embargo, en un monólogo interior al final del manifiesto, se interroga el poeta sobre la experiencia de la escritura, sobre el morir a sí mismo para poder nacer como otro en la escritura, de ahí que hable de "una escritura suicida" (73). Evoca Cañas la experiencia de la modernidad poética, de la otredad del yo, del deshacimiento imprescindible para que nazca la voz poética. Con gran lucidez intenta explicar su propia trayectoria interior ante la escritura hasta $\mathrm{La}$ noche de Europa "que cierra un ciclo de más de 40 años [...]" (74). Afirma haber llegado a un momento vital en que la poesía no necesita de la escritura por estar ella en la vida misma: "Desde un crepúsculo hasta el vuelo de la última mosca del verano pueden ser poesía [...]" (76). Parece haber optado Cañas por un retiro entre activo y filosófico que pasa por la intensidad de la contemplación del universo: "Has dejado de ser poeta, eres la poesía del mundo y ya nadie ni nada te desviarán de ese goce silencioso que es no escribir sino mirar y participar de la belleza del mundo [...] y lo celebrarás [...] sin que las palabras se interpongan" (76).

Es éste un tema recurrente en la obra de Dionisio Cañas, el silencio del poema. En su actual etapa de vida en la Mancha, meditando en su bombo ante la campiña manchega y las puestas de sol parece tomar más distancia todavía que antes con el mundillo literario. Le confesó a su antólogo: “[...] debajo de mis pies, el desierto crece”. No se sabe si Dionisio Cañas volverá a escribir un poemario. Lo cierto es que en la misma entrevista de fines de los 2000 reconocía: "Ah, y vamos a dejarnos de tonterías: en poesía uno siempre termina follando con uno mismo, y no hay nada que nos complazca más que nuestra propia mano...escribiendo." ${ }^{15}$

\section{Conclusión: “ Li lasciamo annegare, per negare”16}

La frase del escritor italiano, Erri de Luca, postula la responsabilidad ética de Europa. Evelyne Ritaine en el artículo " Migrants morts, des fantômes en Méditerranée » se interroga acerca del doble significado de esta frase: " "Nous les laissons se noyer, pour nier": Entend-il par là pour les nier (comme s'ils n'avaient jamais existé), ou bien pour nier "en bloc" (nier toute responsabilité) ? ${ }^{17}$ Sea como sea, invita Erri de Luca a preservar la memoria de los muertos en el Mediterráneo. El texto de Dionisio Cãnas (llámese poemario o no) se inserta entre los numerosos testimonios que desean luchar contra el olvido y la negación, tiene su lugar dentro de las creaciones de artistas que están re-construyendo la memoria de los olvidados e invisibles. Evelyne Ritaine da cuenta de tal toma de conciencia y del movimiento ciudadano que se opera en las mismas puertas de Europa ante la urgencia humanitaria: "Une lutte citoyenne se déroule ainsi aux frontières de l'Union européenne pour que les droits humains des migrants disparus, et de leurs familles, soient respectés. $»^{18}$

En el diario "Cuaderno de Lesbos, el poeta da cuenta de ello": "27-01-2016 [...] Lo que está ocurriendo en Lesbos es un fenómeno nuevo dentro de Europa: la sociedad civil está haciendo lo que los gobiernos europeos no hacen: crear campamentos alternativos a los oficiales para acoger y ayudar a los refugiados que llegan en las pateras". (39) 

y colectiva, mientras va redactando un poema conectado con el proyecto. Solo que va a ser éste el último libro poético, así lo anuncia el yo, se despide de la escritura poética, no de la poesía, porque la va a vivir y gozar. Por consiguiente, es legítimo ver al final este libro como un testamento poético en el que se realiza la recusación de la escritura poética institucionalizada, como producto mercantil en las tantas ferias del libro, recusación igualmente de la figura del autor en provecho de acciones colectivas como la del taller y de la escritura colectiva. Por eso es posible leer al final este poema a la manera de un coro: multiplicidad de voces que llaman, protestan y gritan ante las urgencias de todo tipo. Domina una fuerte vertiente coral (dimensión inter y metatextual) que se manifiesta a todas luces en la puerta 4, "Puerta de la herida", del CD. No obstante, conviene interrogarse acerca del alcance de un proyecto alternativo de tipo performance, hace falta plantear la cuestión de su performatividad. mismo tiempo de la poesía y de los resortes de la escritura. No renuncia Cañas a la escritura, a su poder, a los sortilegios de la materia sonora, vocal, aquí generados por las repeticiones constantes (múltiples paronomasias, rimas internas, anáforas...), propias del ritmo de una letanía tanto como de una elegía. Y forman las tres noches una auténtica elegía, es un planctus en el que se llora a los muertos del Mediterráneo. Ahora el haber interrumpido la continuidad del planctus con el diario y con el texto de Torres evita que los discursos políticamente correctos recuperen o asepticen las tres noches asimilándolas a la tradición poética de la elegía. Esas rupturas construyen un significado crítico: permiten entender que los muertos nada tienen que ver con un destino, ni fatalidad alguna sino con una urgencia ignorada o silenciada. Cañas quiere así restituir las voces que denuncian el silencio ante la urgencia. del poeta sobra la cultura valiéndose de esta misma cultura, recurriendo constantemente a ella. Y de hecho, el libro se podría resumir como un tejido o tapiz de citas y referencias, la dimensión intertextual o intermedial lo invade todo a lo largo del libro sin que se haga diferencia alguna entre los poemas, el diario, el manifiesto creando así una unidad a pesar de la hibridez del conjunto. Con ello, Cañas nos invita a revisitar la tradición cultural europea (occidental) y su historia para significar mejor la contradicción con la situación de urgencia de los refugiados.

En cuanto a la vertiente metatextual participa de lo inteligible de los acontecimientos, de la urgencia, en la medida en que invita al lector a salir de su zona de confort como lector, le invita a cuestionarse acerca de su postura de voyeur (tema recurrente en la obra de (añas), aquí lo formula tajantemente): “Somos una sociedad de mirones, de voyeurs [...]" (42). El poeta se vale de estas mismas armas contra la sociedad del espectáculo al crear un objeto tan impactante e indefinible, totalmente irrecuperable como es La noche de Europa: el libro, el CD y el proyecto rozan con la performance, la teatralidad, la espectacularidad, la provocación.

Este libro fue escrito en parte dentro de la urgencia, en circunstancias de urgencia absoluta, viendo el poeta la urgencia humanitaria, viviendo el desastre y tratando de montar una acción. "La poesía es algo que une a la gente. Con la poesía engancho a personas desmitificando el papel del poeta" afirmó Dionisio Cañas en una entrevista en $2017^{19}$. Quizás cumpla la escritura un papel terapéutico en el mismo momento de la acción y ante lo trágico de la urgencia. Es el libro un diario que presenta una dimensión 
íntima, es el diario personal de un hombre (cuenta su encuentro amoroso con Kamal, un militar irakí). A posteriori, el propio poeta resume su experiencia de la urgencia vivida y del encuentro con el acontecimiento hablando de "[...] un naufragio emocional" (51). El sustantivo, al establecer una analogía con la urgencia vital de los refugiados, sugiere la urgencia del mismo testimonio mediante la escritura. Aquello explica la hibridez total de texto, la discursividad caótica, casi delirante del yo poético, también forman parte de una voluntad de concientización que pasa por el choque con el lector y consigo mismo. Es un ejercicio radical, un discurso poético y político en que Dionisio Cañas aúna lo autobiográfico y lo universal en una reflexión sin concesión alguna.

55 Constituye este poema singular un testimonio impactante de una urgencia paradójica ya que lleva tiempo existiendo en el Mediterráneo, es una urgencia que ha dejado de serlo en las noticias siendo algo recurrente, cotidiano, banalizado. Los periodistas que dieron cuenta de las presentaciones que hizo Cañas del libro lo subrayan

Dionisio Cañas ha puesto negro sobre blanco aquellas imágenes que a diario vomita la televisión. Pateras, desesperación, niños en brazos de adultos o reuniones de ministros negociando cupos de refugiados que los gobiernos nunca cumplen. ${ }^{20}$

Contra esta mediatización repetitiva que vacía lo real de su contenido y de su impacto, el libro rescata y preserva las huellas precisas de lo que pasa día tras día en las mismas puertas de Europa; igual hacen algunos fotógrafos en la isla de Lesbos documentando la urgencia trágica como lo relata Cañãs:

A los cadáveres sin papeles de identidad se les entierra con la fecha en que han sido encontrados ahogados. Un fotógrafo local ha hecho una foto de una de esas lápidas en que dos hombres han sido enterrados como si no tuvieran pasado, solo una fecha, la de su entierro. (39)

Evoca el poeta el caso de Hussein un joven argelino muy enfermo, encerrado "indefinidamente" por no ser considerado como refugiado y del cual afirma "Cuando se publique este libro, posiblemente habrá muerto" (38); luego cuenta cómo durante el Taller Hussein ha dibujado un gran corazón y ha escrito en árabe una frase: "La vida se va y quedan los recuerdos, nuestros cuerpos se pudren y quedan nuestros nombres" (39). El poeta Dionisio Cañas al establecer el cómputo de los muertos, al citar su nombre, al contar anécdotas, al restituir sus frases les está dando la palabra a la par que les está elevando un memorial tan cívico como poético para que se conserve algo de ellos. Al hacer eso, construye un poema polifónico, hecho de voces diversas, incluso contrarias, repartidas sobre un tiempo largo y por espacios múltiples. Se aparenta así el poema a una obra hecha por muchos co-autores y leerlo supone entonces aceptar entrar en este entramado de voces, descifrarlo, interpretarlo y construir su propia interpretación. Pone en tensión tanto la noción de autor como la concepción de la recepción. Estelle Zhong Mengual hace eco a tales prácticas cuando postula la posibilidad de «L'art en commun » o el arte compartido ${ }^{21}$; designa por esta expresión prácticas creativas que unen durante un plazo suficientemente largo como para que los universos se comuniquen, artistas, voluntarios, gentes ajenas al mundo de las artes (lo que le pasó a Dionisio Cañas en Grecia con los refugiados y el Taller). Según Estelle Zhong Mengual, los participantes van a co-producir formas o símbolos situados en espacios de la vida cotidiana, apartándose de las áreas del espectáculo organizado desde arriba. "Il s'agit d'un art qui vient questionner la réinvention des conditions et des formes possibles d'un faire collectif $\aleph^{22}$. Dicha co-creación intenta rechazar lo que sería mero encuentro "digestivo" ${ }^{23}$, propio del consumerismo, ya que los espectadores se 
convierten en co-autores, pasando de un papel pasivo a un actuar en la elaboración artística. Sustituyen así un hacer horizontal y colectivo a la verticalidad y egotismo del autor, dueño único de la obra de arte.

Podemos afirmar que el proyecto de Dionisio Cañas presenta puntos de entronque con tal teoría y concepción de un arte que sea colectivo y que cuestione sus mismas condiciones de elaboración. El principio del taller ideado por Cañas consiste en partir de los refugiados para que se expresen, digan sus miedos, descubran sus esperanzas y sus necesidades con palabras más o menos burdas, brutales a veces o ya más trabajadas, según la vivencia y el origen social de cada cual, pero palabras que sean suyas ante todo. La co-construcción de un texto sin jerarquización que valga en las palabras ${ }^{24}$ puede así dejar emerger algo compartido, un "común" para los participantes, un objeto simbólico en el que se reconocen a su manera. Quizás esta nueva forma de pensar la escritura y el arte sea una respuesta a las urgencias de hoy.

\section{NOTAS}

1. Dionisio Cañas, La noche de Europa [2017], Valencia, Amarcord, El petit editor, 2018.

2. Dionisio Cañas, “Cuaderno de Lesbos”, op. cit., p. 51. Las refrencias al poemario se encuentran entre paréntesis en el texto.

3. Particularmente en el artículo «Grammaire africaine» que analiza el vocabulario oficial utilizado para evocar la política colonial de Francia y la incipiente guerra de Argelia: «C'est une écriture que l'on pourrait appeler cosmétique parce qu'elle vise à recouvrir les faits d'un bruit de langage, ou si l'on préfère du signe suffisant du langage.» (Roland Barthes, Mythologies, Paris, Seuil, coll. «Points », 1957, p. 137).

4. Manuel Juliá, el antólogo de Dionisio Cañas, Lugar, antología y nuevos poemas, (Madrid, Hiperión, 2010) comenta su vuelta como un retiro: “[...]su bombo, una choza de piedra entre las viñas donde se retira cuando el bullicio de Tomelloso le aprisiona los tímpanos.” (Ibid, p. 205-206)

5. Claire Laguian, “'El universo te entra por los ojos y te sale por la boca': lo visual en su multiplicidad en La noche de Europa de Dionisio Cañas", "Dionisio Cañas. Vida, Poesía, Arte y Pensamiento", Monograma. Revista Iberoamericana de Cultura y Pensamiento, Fundación Iberoamericana de las Industrias Culturales y Creativas, nº 4, 2019, p. 131-154, en ligne : http:// revistamonograma.com/visual-en-su-multiplicidad-noche-de-europa-dionisio-canas/

6. Se podrá leer una reseña del libro redactada por José Luis Plaza Chillón, ofrece un resumen bastante completo. En https://www.lacavernadeplaton.com/resenasbis/nocheuropa1718.htm

7. En la contracubierta, se lee el comentario siguiente: "Se dice 'voz poética'. Y de eso va esta colección: de voces. De palabras saliendo por la boca. De su música redentora ante tanta lectura aburrida. Poesía igual atonía. Poemas para leer en voz alta. Poemas donde poner el cuerpo y el rostro y palabrear sin parar. Poetas vivos. Poesía con vida." (Dionisio Cañas, La noche de Europa, op. cit., contracubierta.)

8. Manuel Juliá, "Prólogo", in Dionisio Cañas, Lugar, antología y nuevos poemas, op. cit., p.13.

9. Philippe Jaccottet, Une transaction secrète. Lectures de poésie, Paris, Gallimard, NRF, Poésie, 1987, p. 341-342.

10. Pierre Nora, «Le retour de l'évènement" in J. Le Goff et P. Nora (dir.), Faire de l'histoire. Nouveaux problèmes, vol. I, Paris, Gallimard, 1974, p. 210-229. 
11. Alban Bensa, en collab. avec Eric Fassin, «Les sciences sociales face à l'évènement ", $2^{\mathrm{e}}$ partie «Pratiques et fabriques du temps» in Alban Bensa, La fin de l'exotisme Essais d'anthropologie critique, Toulouse, Anarchasis éditions, 2006, p. 147.

12. Alban Bensa, en collab. avec Eric Fassin, «Les sciences sociales face à l'évènement », op. cit., p. 162.

13. Ibid., p. 159.

14. Luis Antonio de Villena, "Decadencias. La noche de Europa". Sin embargo, añade Villena, "Leo al amigo Dionisio como un Boecio ('ultimus romanorum' también yo) que dice adiós a muchas cosas amadas. Tristemente la Filosofía, dulce matrona, no acude a consolarnos". http:// luisantoniodevillena.es/web/articulos/la-noche-europa/, consultado el 19 noviembre 2018.

15. Manuel Juliá, "Paseando con Dionisio Cañas” in Lugar, op. cit., p. 211.

16. Erri De Luca, Noi, carcerieri di viaggiatori. Libreidee.org. www.libreidee.org/2010/03/migrantierri-de-lucanoi-carcerieri-di-viaggiatori/ IN Évelyne RITAINE, « Migrants morts, des fantômes en Méditerranée ", Rhizome, 2017/2 ( $\mathrm{n}^{\circ}$ 64), p. 16-17. URL : https://www.cairn.info/revuerhizome-2017-2.htm-page-16.htm, consulté le 17 novembre 2018.

17. Évelyne RITAINE, « Migrants morts, des fantômes en Méditerranée », op. cit.

18. «Et puis, la mort étant advenue, nombreux sont ceux (journalistes, photographes, créateurs) qui deviennent des veilleurs de mémoire. Pour eux, il y a un impératif éthique : que ces morts ne soient pas oubliés, dans le tragique de l'événement du naufrage, mais aussi dans l'humanité de leur existence. La publication de récits de vie et de photographies de défunts, les commémorations locales (comme le jardin de la mémoire à Lampedusa) sont autant d'actes de remémoration, de luttes contre l'oubli, de refus de l'inéluctable. Les créateurs, eux, travaillent à la transfiguration des traces. [...] Désormais de nombreuses œuvres d'art portent le souvenir des disparus [...]». (Ibid.)

19. Nuria Ribó, “Todos somos refugiados”, El Mundo, 28 febrero 2017.

https://www.elmundo.es/cataluna/2017/02/28/58b5370a22601d40078b4643.html, consultado el 19 noviembre 2018.

20. Nuria Ribó, “Todos somos refugiados”, El Mundo, 28 febrero 2017.

https://www.elmundo.es/cataluna/2017/02/28/58b5370a22601d40078b4643.html, consultado el 19 noviembre 2018.

21. Baptiste Morizot, Estelle Zhong Mengual, Esthétique de la rencontre, Paris, Seuil, 2018, p. 131.

22. Ibid.

23. Ibid.

24. Dionisio Cañas lo postula así: "El poeta debe aceptar la palabra de donde y de quien venga [...] Una de las primeras reglas para ser poeta es despojarse de todo prejuicio respecto a las jerarquías del lenguaje poético. No se trata de un 'todo vale' sino de un 'todo es valioso' para un primer movimiento en la escritura" in Lugar, antología y nuevos poemas, op. cit., p. 209.

\section{RESÚMENES}

El estudio se propose analizar el ultimo libro poético de Dionisio Cañas y cuestionar primero su mismo género de poemario. Luego cabe interrogar la conexión entre la forma externa del libro y la escritura poética que están en tensión con la situación de producción (urgencia). Al final 
conviene estudiar la cuestión de la representación de la urgencia mediante la palabra poética. Conduce aquello a cuestionar el papel social del poeta y, más ampliamente del artista, ante la urgencia.

Cette étude entend analyser le dernier recueil poétique de Dionisio Cañas et questionner d'entrée le genre même dont il relève. Puis il s'agit de réfléchir au lien existant entre la forme externe du livre et l'écriture poétique qui sont en tension avec la situation de production (l'urgence). Enfin il convient d'examiner la question de la représentation de l'urgence par la parole poétique. Cela conduit à interroger le rôle social du poète, et de l'artiste plus largement, face à l'urgence.

ÍNDICE

Mots-clés: Cañas (Dionisio), écriture poétique d'urgence, urgence des réfugiés, évènement, intelligibilité de l'urgence, rôle social de l'art

Palabras claves: Cañas (Dionisio), escritura poética urgente, urgencia de los refugiados, acontecimiento, inteligibilidad, papel social del arte

\section{AUTOR \\ CLAUDIE TERRASSON}

Université Gustave Eiffel, LISAA EA 4120 